\title{
Postoperative pain and patient-controlled epidural analgesia-related adverse effects in young and elderly patients: a retrospective analysis of 2,435 patients
}

\author{
This article was published in the following Dove Press journal: \\ Journal of Pain Research \\ 12 April 2017 \\ Number of times this article has been viewed
}

\author{
Jae Chul Koh \\ Young Song \\ So Yeon Kim \\ Sooyeun Park \\ Seo Hee Ko \\ Dong Woo Han
}

Department of Anesthesiology and Pain Medicine, Anesthesia and Pain Research Institute, Yonsei University College of Medicine, Seoul, South Korea
Correspondence: Dong Woo Han Department of Anesthesiology and Pain Medicine, Gangnam Severance Hospital, Yonsei University College of Medicine, 2II Eonju-ro, Gangnam-gu, Seoul I35-

720 , South Korea

Tel +82 220193529

Fax +82 234630940

Email hanesth@yuhs.ac

\begin{abstract}
In this retrospective study, data of 2,435 patients who received fentanyl and ropivacaine-based patient-controlled epidural analgesia (PCEA) for pain relief after elective surgery under general or spinal anesthesia were reviewed. Differences in postoperative pain, incidence of patient-controlled analgesia (PCA)-related adverse effects, and risk factors for the need for rescue analgesics for 48 hours postsurgery in young (age 20-39 years) and elderly (age $\geq 70$ years) patients were evaluated. Although there were no significant differences in postoperative pain intensity between the two groups until 6 hours postsurgery, younger patients experienced greater postoperative pain intensity compared with older patients 6-48 hours postsurgery. While younger patients exhibited greater incidence of numbness, motor weakness, and discontinuation of PCA postsurgery, elderly patients exhibited greater incidence of hypotension, nausea/ vomiting, rescue analgesia, and antiemetic administration. Upon multivariate analysis, low fentanyl dosage and history of smoking were found to be associated with an increased need for rescue analgesia among younger patients, while physical status classification III/IV and thoracic surgery were associated with a decreased need for rescue analgesia among the elderly. Discontinuation of PCA was more frequent among younger patients than the elderly $(18.5 \%$ vs $13.5 \%, P=0.001)$. Reasons for discontinuation of PCA among young and elderly patients, respectively, were nausea and vomiting (6.8\% vs $26.6 \%)$, numbness or motor weakness $(67.8 \%$ vs $11.5 \%$ ), urinary retention ( $7.4 \%$ vs $8.7 \%$ ), dizziness ( $2.2 \%$ vs $5.2 \%)$, and hypotension $(3.1 \%$ vs $20.3 \%$ ). In conclusion, PCEA was more frequently associated with numbness, motor weakness, and discontinuation of PCA in younger patients and with hypotension, nausea/vomiting, and a greater need for rescue analgesics/antiemetics among elderly patients. Therefore, in order to minimize the adverse effects of PCEA and enhance pain relief, different PCEA regimens and administration/prevention strategies should be considered for young and elderly patients.

Keywords: adverse effect, age, elderly, epidural analgesia, pain management, patient-controlled analgesia
\end{abstract}

\section{Introduction}

Patient-controlled epidural analgesia (PCEA) is a very effective method of postoperative pain control in various surgeries. Epidural analgesia (EA) with a local anesthetic in combination with an opioid provides effective pain relief and might improve postoperative outcomes. ${ }^{1}$ However, administration of high dosages of opioids via the epidural route can cause nausea, vomiting, and respiratory depression. ${ }^{2}$ In addition, excessive administration of local anesthetics can cause adverse effects, such as hypotension and motor blockade, thus compromising postoperative mobility and delaying postoperative recovery. ${ }^{3}$ 
Elderly patients comprise a large and rapidly increasing proportion of surgical patients. Proper assessment and management of postoperative pain and patient-controlled analgesia (PCA)-related adverse effects are important, because of the high rates of morbidity and mortality associated with inadequate pain control in elderly patients. ${ }^{4}$ The pharmacokinetic and pharmacodynamic properties of a pharmacological agent vary with increasing patient age. ${ }^{5}$ Elderly patients exhibit decreased hepatic/renal excretion and cardiac output and increased susceptibility to central nervous systemactive medications. They also exhibit increased body fat and consequently an altered volume of distribution to drugs..$^{6-8}$ In addition, because of changes in cognitive function and behavioral/socioeconomic conditions, elderly patients exhibit altered expression of pain. ${ }^{8,9}$ Therefore, despite exposure to the same procedure or drugs, the effectiveness and adverse effects of PCEA among elderly patients might differ from those among younger patients. However, to the best of our knowledge, no study has evaluated these differences in PCEA between young and elderly patients. Therefore, in this retrospective study, we investigated differences in postoperative pain, incidence of PCA-related adverse effects, risk factors for the need for rescue analgesics, and reasons for discontinuation of PCA during a 48-hour postoperative period between young and elderly patients who received fentanyl and ropivacaine-based PCEA.

\section{Subjects and methods}

This study was approved by the institutional review board of Gangnam Severance Hospital, Seoul, South Korea (3-20160134) and registered at ClinicalTrials.gov (NCT02849730). The requirement for written informed consent was waived for this medical record-review study under the regulations of the institutional review board. Patient-identification data were encoded and scrambled using a restricted computer to protect the privacy of all subjects.

In our hospital, a PCA service team consisting of two specialized nurses collected multidisciplinary clinical data from all patients using PCEA during a 48-hour postoperative period since 2010. These data included clinical outcomes, such as pain intensity, additional rescue analgesic/antiemetic administration, and adverse effects, including nausea/vomiting, numbness/weakness, sedation, hypotension, headache/ dizziness, pruritus, and discontinuation of PCA. Intensities of pain and nausea were both measured using an 11-point numeric rating scale (NRS; 0-10: $0=$ no pain/nausea, $10=$ worst imaginable pain/nausea). Rescue analgesics/antiemetics were administered according to our institutional guidelines.
For pain scores $>4$, rescue analgesia was administered with $30 \mathrm{mg}$ ketorolac (Keromin; Hana Pharm, Seoul, South Korea) or $25 \mathrm{mg}$ pethidine (Jeil Pharmaceutical, Seoul, South Korea). Rescue antiemetics were administered at nausea scores $>4$; $10 \mathrm{mg}$ metoclopramide (Macperan; Dong Wha Pharmaceutical, Seoul, South Korea) was administered as the first-line rescue antiemetic, followed by $4 \mathrm{mg}$ ondansetron (Onseran; Yuhan, Seoul, South Korea) or $0.3 \mathrm{mg}$ ramosetron (Nasea; Astellas Pharma, Tokyo, Japan) when refractory.

Data of patients who received PCEA for pain following elective surgery under general or spinal anesthesia between September 2010 and November 2015 were reviewed. Patients were divided into two groups according to age: young (20-39 years) and elderly ( $\geq 70$ years) groups. Patients aged $40-69$ years and those aged $<20$ years were excluded, as were patients who received routine analgesics/antiemetics and those with incomplete data.

PCEA was delivered through a disposable PCA pump (Ambix Anaplus [Fresenius Kabi, Bad Homburg, Germany] or Accufuser Plus [Woo Young Medical, Jincheon, South Korea]) with fentanyl and ropivacaine. Dosages of fentanyl $(1-10 \mu \mathrm{g} / \mathrm{mL})$ and ropivacaine $(0.1 \%-0.25 \%)$ for PCA, background infusion rate $(2$ or $5 \mathrm{~mL} / \mathrm{h})$, on-demand bolus dose $(0.5-2 \mathrm{~mL})$, and lockout time (15 or 30 minutes) were determined by the anesthesiologists who induced anesthesia during surgery. Demographic and clinical variables - age, sex, body mass index, American Society of Anesthesiologists (ASA) physical status, history of smoking, motion sickness, and postoperative nausea/vomiting - were evaluated. In addition, anesthesia and surgery-related variables, including the type and duration of anesthesia and type of surgery (abdominal, thoracic, orthopedic, or urogenital), were investigated. All postoperative variables were recorded at $0-6$ (including postanesthesia care unit stay), 6-12, 12-18, 18-24, and 24-48 hours postoperatively.

Postoperative pain intensity using the NRS was compared between groups. During the 48 postoperative hours, the percentage of patients who required rescue analgesics or antiemetics at least once was investigated, as well as incidence of any adverse effects. Factors associated with rescue analgesic requirements were investigated.

Statistical analyses were performed using SAS 9.2 software (SAS Institute Inc., Cary, NC, USA). Demographic and anesthesia/surgery-related variables were analyzed by independent $t$-test or Mann-Whitney $U$-test after the Shapiro-Wilk test for normality for continuous variables and $\chi^{2}$ or Fisher's exact test for categorical variables. Univariate logistic regression analyses were performed to identify factors 
related to the need for rescue analgesia and discontinuation of PCA. Factors with $P$-values $<0.05$ in the univariate logistic regression model, as well as those considered clinically important, were evaluated by multiple logistic regression analysis. Odds ratios and $95 \%$ confidence intervals were estimated, and $P$-values $<0.05$ were considered statistically significant.

\section{Results}

Among a total of 7,448 patients, data of 2,435 patients were included in the present analysis. The young and elderly groups comprised 1,344 and 1,091 patients, respectively. While 403 patients were excluded because of routine use of analgesics/antiemetics, 17 were excluded because of incomplete data (Figure 1).

Patient demographic characteristics and details regarding PCA, anesthesia, and surgery are presented in Table 1. Elderly patients exhibited lower body mass index and higher incidence of diabetes mellitus and history of smoking than younger patients. The proportion of female patients and incidence of spinal anesthesia and motion sickness among younger patients were higher compared to elderly patients. Elderly patients received lower fentanyl dosage and higher ropivacaine dosage per hour than young patients. The most common type of surgery among young and elderly patients was abdominal ( $81.7 \%$ and $44.4 \%$, respectively). Thoracic $(9.2 \%$ vs $1.7 \%)$, lower extremity ( $39.5 \%$ vs $15.6 \%)$, and urogenital ( $7 \%$ vs $0.9 \%)$ surgeries were more common among the elderly group than the younger group of patients.

With regard to postoperative pain profiles, while younger patients exhibited higher NRS pain scores than the elderly at 6-48 postoperative hours, there was no statistically significant difference in NRS pain score at 0-6 hours between the two groups (Table 2). However, more elderly patients used rescue analgesics than young patients in the early postoperative period (Figure 2).

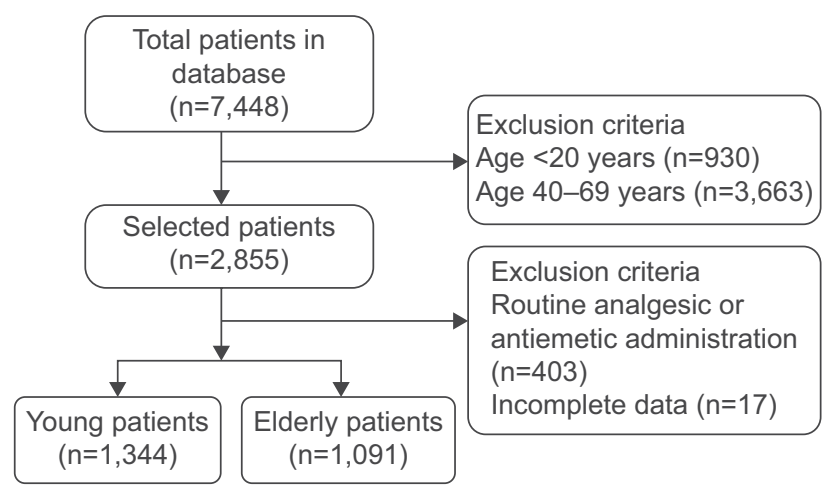

Figure I Flowchart indicating patient selection and exclusion criteria.
Table I Preoperative characteristics of patients using epidural PCA

\begin{tabular}{|c|c|c|c|}
\hline $\begin{array}{l}\text { Preoperative } \\
\text { characteristics }\end{array}$ & $\begin{array}{l}\text { Young patients } \\
(n=I, 344)\end{array}$ & $\begin{array}{l}\text { Elderly } \\
\text { patients } \\
(n=I, 09 I)\end{array}$ & $P$-value \\
\hline \multicolumn{4}{|l|}{ Patient characteristics } \\
\hline Women* & $\mathrm{I}, 040(77.4)$ & $588(48.2)$ & $<0.001$ \\
\hline Age (years)* & $31.9 \pm 4.7$ & $74.6 \pm 3.8$ & $<0.001$ \\
\hline BMI $\left(\mathrm{kg} / \mathrm{m}^{2}\right)^{*}$ & $25.3 \pm 3.9$ & $23.9 \pm 3.4$ & $<0.001$ \\
\hline ASA physical status* & & & $<0.001$ \\
\hline I & $830(63)$ & $179(16.8)$ & \\
\hline II & $463(35.1)$ & $583(54.8)$ & \\
\hline III & $24(1.8)$ & $291(27.4)$ & \\
\hline IV & $\mathrm{I}(0.1)$ & II (I) & \\
\hline \multicolumn{4}{|l|}{ Mixed PCA amounts } \\
\hline Fentanyl $(\mu g / h)^{*}$ & $11.7 \pm 4.4$ & $11 \pm 6$ & 0.003 \\
\hline Ropivacaine $(\mathrm{mg} / \mathrm{h})^{*}$ & $7.5 \pm 1.5$ & $8 \pm 2.8$ & $<0.001$ \\
\hline \multicolumn{4}{|l|}{ Medical history } \\
\hline Hypertension* & $22(1.6)$ & $515(47.2)$ & $<0.001$ \\
\hline Diabetes mellitus* & $16(1.2)$ & $227(20.8)$ & $<0.001$ \\
\hline Motion sickness* & $128(9.5)$ & $52(4.8)$ & $<0.001$ \\
\hline Previous PONV & $12(0.9)$ & $10(0.9)$ & 0.951 \\
\hline Smoking* & $83(6.2)$ & $221(20.3)$ & $<0.001$ \\
\hline \multicolumn{4}{|l|}{$\begin{array}{l}\text { Anesthesia-related } \\
\text { conditions }\end{array}$} \\
\hline Anesthesia duration (minutes)* & $147 \pm 104.7$ & $214 \pm 130.9$ & $<0.001$ \\
\hline Type of anesthesia* & & & $<0.001$ \\
\hline General & $397(29.8)$ & $674(62.3)$ & \\
\hline Spinal & $934(70.2)$ & $408(37.7)$ & \\
\hline Type of surgery* & & & $<0.001$ \\
\hline Abdominal & I,083 (8I.7) & $470(43.4)$ & \\
\hline Thoracic & $23(1.7)$ & $97(9.2)$ & \\
\hline Lower extremities & $206(15.3)$ & $418(39.5)$ & \\
\hline Spinal & $\mathrm{I}(0.1)$ & 0 & \\
\hline Urogenital & $12(0.9)$ & $74(7)$ & \\
\hline
\end{tabular}

Notes: $* P<0.05$. Values are presented as mean \pm standard deviation or number $(\%)$ of patients.

Abbreviations: PCA, patient-controlled analgesia; BMI, body mass index; ASA, American Society of Anesthesiologists; PONV, postoperative nausea and vomiting.

Table 2 Postoperative numeric rating scale for pain intensity

\begin{tabular}{|c|c|c|c|}
\hline $\begin{array}{l}\text { Postoperative } \\
\text { hours }\end{array}$ & $\begin{array}{l}\text { Young patients } \\
(n=I, 344)\end{array}$ & $\begin{array}{l}\text { Elderly patients } \\
(n=I, 09 I)\end{array}$ & $P$-value \\
\hline $0-6$ hours & $4.2 \pm 3.1$ & $4.3 \pm 3.1$ & 0.921 \\
\hline $6-12$ hours* & $4.8 \pm 2.6$ & $4.1 \pm 2.9$ & $<0.001$ \\
\hline $12-18$ hours* & $4.1 \pm 2.3$ & $3.3 \pm 2.6$ & $<0.001$ \\
\hline I8-24 hours* & $3.5 \pm 2.1$ & $3.0 \pm 2.4$ & $<0.001$ \\
\hline 24-48 hours* & $3.2 \pm 1.8$ & $3.1 \pm 2.1$ & $<0.001$ \\
\hline
\end{tabular}

Notes: $* P<0.05$. Values are presented as mean \pm standard deviation.

With regard to adverse effects, the incidence of numbness and motor weakness among younger patients was higher compared to the elderly. However, the incidence of sedation, hypotension, and nausea and vomiting among the elderly was higher compared to younger patients. The elderly patients also exhibited more frequent use of rescue analgesics and antiemetics compared with the younger patients. Discontinuation of PCA was more frequently observed among younger 


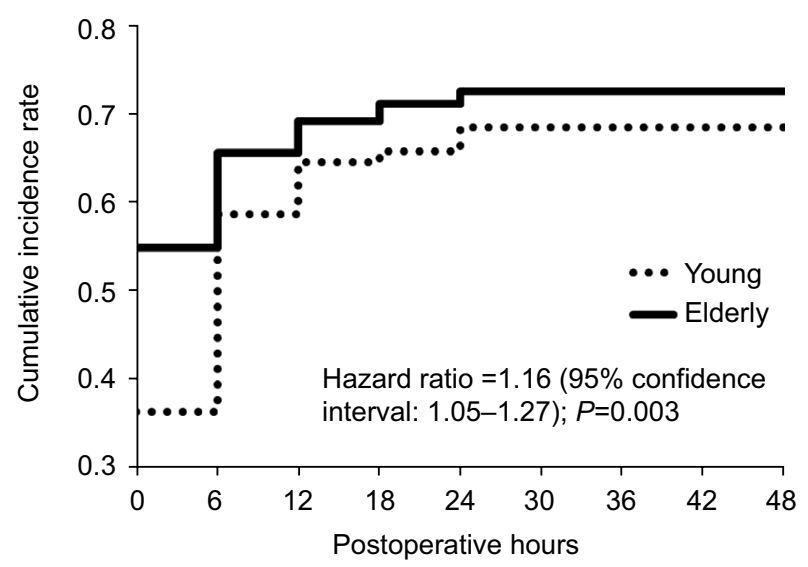

Figure 2 Kaplan-Meier curve demonstrating the incidence rate of patients who used rescue analgesics at least once during the study period.

patients than among the elderly $(18.5 \%$ vs $13.5 \%, P=0.001$; Table 3). Reasons for discontinuation of PCA among the young and elderly patients were nausea and vomiting $(6.8 \%$ vs $26.6 \%)$, numbness or motor weakness $(67.8 \%$ vs $11.5 \%)$, urinary retention ( $7.4 \%$ vs $8.7 \%$ ), dizziness ( $2.2 \%$ vs $5.2 \%$ ), and hypotension ( $3.1 \%$ vs $20.3 \%$ ).

Univariate logistic regression analysis was performed for factors associated with rescue analgesic requirements
Table 3 Incidence of epidural PCA-related complications in young and elderly patients

\begin{tabular}{llll}
\hline Complications & $\begin{array}{l}\text { Young patients } \\
(\mathbf{n}=\mathbf{I}, \mathbf{3 4 4})\end{array}$ & $\begin{array}{l}\text { Elderly patients } \\
(\mathbf{n}=\mathbf{I}, \mathbf{0 9} \mathbf{)})\end{array}$ & P-value \\
\hline Numbness* & $509(37.9)$ & $54(4.9)$ & $<0.00 \mathrm{I}$ \\
Motor weakness* & $153(1 \mathrm{I} .4)$ & $\mathrm{II}(\mathrm{I})$ & $<0.00 \mathrm{I}$ \\
Urinary retention & $78(6 . \mathrm{I})$ & $66(6.7)$ & 0.536 \\
Headache & $20(\mathrm{I} .5)$ & $9(0.8)$ & 0.134 \\
Dizziness & $54(4)$ & $52(4.8)$ & 0.368 \\
Sedation* & $2(0.2)$ & $15(1.4)$ & $<0.00 \mathrm{I}$ \\
Pruritus & $40(3)$ & $37(3.4)$ & 0.56 \\
Hypotension* & $20(1.5)$ & $78(7.2)$ & $<0.00 \mathrm{I}$ \\
Nausea/vomiting* & $144(10.7)$ & $210(19.3)$ & $<0.00 \mathrm{I}$ \\
Discontinuation of PCA* & $248(18.5)$ & $147(13.5)$ & $0.00 \mathrm{I}$ \\
Rescue analgesics* & $920(68.5)$ & $792(72.5)$ & 0.03 \\
Rescue antiemetics* & $32(2.4)$ & $64(5.9)$ & $<0.00 \mathrm{I}$ \\
\hline
\end{tabular}

Notes: $* P<0.05$. Values are presented as number (\%) of patients.

Abbreviation: PCA, patient-controlled analgesia.

(Table 4). Factors with $P$-values $<0.05$ and those considered clinically important were evaluated by multiple logistic regression analysis. Upon multivariate analysis, low fentanyl dosage per hour and history of smoking were found to be related to increased use of rescue analgesia among young patients. In contrast, ASA classification III/V and thoracic/

Table 4 Univariate analysis of factors associated with rescue analgesic requirements

\begin{tabular}{|c|c|c|c|c|}
\hline \multirow[b]{2}{*}{ Predictors } & \multicolumn{2}{|c|}{ Young patients $(n=1,344)$} & \multicolumn{2}{|c|}{ Elderly patients $(n=I, 09 I)$} \\
\hline & OR (95\% Cl) & $P$-value & OR $(95 \% \mathrm{Cl})$ & $P$-value \\
\hline Female sex & $0.98(0.75-1.29)$ & 0.899 & $1.98(1.5-2.6)^{*}$ & $<0.001$ \\
\hline BMI & $0.98(0.96-1.01)$ & 0.258 & $1.05(1.01-1.09)^{*}$ & 0.019 \\
\hline \multicolumn{5}{|l|}{ ASA physical status } \\
\hline $\mathrm{I}$ & I (reference) & & I (reference) & \\
\hline 2 & I (0.78-I.27) & 0.974 & $0.74(0.49-1.1)$ & 0.133 \\
\hline 3 & $0.64(0.28-1.47)$ & 0.292 & $0.61(0.4-0.94)^{*}$ & 0.026 \\
\hline 4 & NA & 1 & $0.33(0.1-1.15)$ & 0.083 \\
\hline Fentanyl $(\mu \mathrm{g} / \mathrm{h})$ & $0.98(0.95-1)$ & 0.056 & $0.94(0.92-0.97)^{*}$ & $<0.001$ \\
\hline Ropivacaine (mg/h) & $0.99(0.92-1.07)$ & 0.657 & $1.01(0.96-1.06)$ & 0.605 \\
\hline Total PCA amount (mL) & $I(I-I)$ & 0.648 & $I(I-I)$ & 0.596 \\
\hline History of DM & $0.77(0.28-2.12)$ & 0.607 & $0.98(0.7 \mid-1.36)$ & 0.923 \\
\hline History of hypertension & $0.99(0.4-2.44)$ & 0.978 & $1.20(0.92-1.56)$ & 0.192 \\
\hline History of motion sickness & $0.9(0.6 \mathrm{I}-\mathrm{I} .33)$ & 0.601 & $0.47(0.16-1.37)$ & 0.172 \\
\hline History of PONV & $2.32(0.51-10.63)$ & 0.279 & $3.44(0.43-27.24)$ & 0.242 \\
\hline Smoking history & $1.7 \mid(I-2.93)^{*}$ & 0.048 & $0.63(0.46-0.86)^{*}$ & 0.004 \\
\hline Anesthesia duration (minutes) & $I(I-I)$ & 0.496 & $0.99(0.99-1)$ & 0.602 \\
\hline \multicolumn{5}{|l|}{ Type of anesthesia } \\
\hline General & I (reference) & & I (reference) & \\
\hline Regional & I.0I (0.79-I.3) & 0.912 & $3.17(2.3 \mid-4.34)^{*}$ & $<0.001$ \\
\hline \multicolumn{5}{|l|}{ Type of surgery } \\
\hline Abdominal & I (reference) & & I (reference) & \\
\hline Thoracic & $0.85(0.36-2.03)$ & 0.722 & $0.55(0.35-0.86)^{*}$ & 0.008 \\
\hline Lower extremity & I.II (0.8-1.54) & 0.536 & $2.61(1.86-3.65)^{*}$ & $<0.001$ \\
\hline Spinal & NA & I & - & - \\
\hline Urogenital & $0.46(0.15-1.42)$ & 0.176 & $0.49(0.3-0.8)^{*}$ & 0.005 \\
\hline
\end{tabular}

Notes: $* P<0.05$. '-' indicates no patient.

Abbreviations: OR, odds ratio; Cl, confidence interval; BMI, body mass index; ASA, American Society of Anesthesiologists; NA, not available; PCA, patient-controlled analgesia; DM, diabetes mellitus; PONV, postoperative nausea/vomiting. 
urogenital surgery (in comparison with abdominal surgery) were found to be related to decreased use of rescue analgesia among elderly patients (Table 5).

\section{Discussion}

In this retrospective study, we evaluated postoperative pain and PCEA-related adverse effects and identified risk factors for the need for rescue analgesia and reasons for discontinuation of PCEA among young and elderly patients. The 6- to 48-hour postsurgery NRS pain scores of elderly patients were lower compared to those of the younger patients. While the younger patients exhibited higher incidence of numbness and motor weakness than the elderly, sedation, hypotension, and nausea and vomiting were more common among elderly patients than the younger ones. Low fentanyl dosage and history of smoking were associated with an increased need for rescue analgesia among young patients, while physical status classification III/IV and thoracic surgery were associated with a decreased need for rescue analgesia among elderly patients.

In elderly patients, decrease in myelinated fibers in the dorsal and ventral roots, which results in increased sensitivity to local anesthetics, ${ }^{10}$ reduction in epidural fat, and increased permeability, may cause EA to be more potent than in younger patients. ${ }^{10,11}$ This might explain the NRS pain scores of the elderly patients being lower compared to the younger patients during the postoperative 6-48 hours in the present study. Additionally, the proportion of patients who underwent abdominal surgery, which induces intense postoperative pain, ${ }^{12}$ in the younger group was higher compared to the elderly group. However, there was no significant difference in NRS pain score between the two groups during the postoperative 6-hour period, which might have been because of differences in type of anesthesia between the two groups. The proportion of patients who received spinal anesthesia in the younger group was higher compared to the elderly group. Therefore, despite the relatively low potency of PCEA in young patients, the lower overall NRS pain scores of the younger group in comparison with the elderly group might have been because of the residual effect of spinal anesthesia during the immediate postoperative period.

The overall proportion of patients who required rescue analgesia at least once during the postoperative 48-hour period in the present study $(70.31 \%)$ was higher compared to patients with postoperative IV PCA in our previous study $(51.28 \%) .{ }^{13}$ In terms of effectiveness of pain control, PCEA did not appear to be superior to IV PCA, except during the immediate postoperative period in the present study, which is not consistent with the results of previous studies. ${ }^{14,15}$ This might have been because PCEA was usually administered to patients who were expected to experience severe postoperative pain. Paradoxically, the incidence of rescue analgesia was higher among the elderly patients than the younger

Table 5 Multivariate analysis of factors associated with rescue analgesic requirements

\begin{tabular}{|c|c|c|c|c|}
\hline \multirow[t]{2}{*}{ Predictors } & \multicolumn{2}{|c|}{ Young patients $(n=1,344)$} & \multicolumn{2}{|c|}{ Elderly patients $(n=I, 09 I)$} \\
\hline & OR (95\% CI) & P-value & OR (95\% CI) & P-value \\
\hline Female sex & I.I 6 (0.78-I.73) & 0.457 & I.02 (I.7I-I.47) & 0.907 \\
\hline BMI & $0.98(0.95-1.02)$ & 0.286 & I (0.95-I.05) & 0.941 \\
\hline \multicolumn{5}{|l|}{ ASA physical status } \\
\hline I & I (reference) & & I (reference) & \\
\hline 2 & $\mathrm{I} .04(0.8 \mathrm{I}-\mathrm{I} .35)$ & 0.738 & $0.76(0.5-1.16)$ & 0.202 \\
\hline 3 & $0.56(0.23-1.33)$ & 0.185 & $0.61(0.38-0.99)^{*}$ & 0.047 \\
\hline 4 & NA & I & $0.26(0.07-0.95)^{*}$ & 0.042 \\
\hline Fentanyl $(\mu g / h)$ & $0.97(0.95-1)^{*}$ & 0.046 & $0.98(0.95-1.01)$ & 0.139 \\
\hline Ropivacaine (mg/h) & $0.99(0.92-1.08)$ & 0.886 & $\mathrm{I} .03(0.97-1.09)$ & 0.38 \\
\hline History of DM & $0.65(0.23-1.86)$ & 0.426 & $\mathrm{I} .05(0.72-\mathrm{I} .53)$ & 0.809 \\
\hline History of hypertension & $1.06(0.42-2.7)$ & 0.898 & I.I4 (0.83-I.55) & 0.424 \\
\hline Smoking history & $2.63(1.37-5.04)^{*}$ & 0.004 & I.0I (0.68-I.48) & 0.977 \\
\hline \multicolumn{5}{|l|}{ Type of anesthesia } \\
\hline General & I (reference) & & I (reference) & \\
\hline Regional & $0.99(0.73-1.33)$ & 0.927 & $0.49(0.05-4.48)$ & 0.53 \\
\hline \multicolumn{5}{|l|}{ Type of surgery } \\
\hline Abdominal & I (reference) & & I (reference) & \\
\hline Thoracic & $0.64(0.25-1.66)$ & 0.36 & $0.58(0.36-0.93)^{*}$ & 0.025 \\
\hline Lower extremity & I.II (0.72-I.7I) & 0.648 & $4.9(0.53-45.07)$ & 0.161 \\
\hline Spinal & NA & I & - & - \\
\hline Urogenital & $0.53(0.16-1.74)$ & 0.297 & $0.54(0.32-0.91)$ & 0.019 \\
\hline
\end{tabular}

Notes: $* P<0.05$; ' - ' indicates no patient.

Abbreviations: OR, odds ratio; Cl, confidence interval; BMI, body mass index; ASA, American Society of Anesthesiologists; NA, not available; DM, diabetes mellitus. 
ones, despite the lower NRS scores of the former. One of the possible reasons could be that a greater proportion of elderly patients required rescue analgesia in the immediate postoperative period (54.8\% vs $36.3 \%$ ) in comparison with the younger patients, whose requirement for rescue analgesia was lower, because of the residual analgesic effect of spinal anesthesia during the period in question. However, the difference between the two groups did not appear to be clinically relevant.

Among younger patients, low fentanyl dosage and history of smoking were related to the use of rescue analgesia. There are several reports of increased postoperative pain and analgesic requirements among smokers. Though the precise mechanism is not yet clear, changes in neuromodulation due to chronic exposure to nicotine and depression or stress because of smoking cessation appear to be related to the increased need for rescue analgesia among smokers. ${ }^{16-18}$ Among elderly patients, ASA class III/IV and thoracic/urogenital surgery were associated with lower need of rescue analgesia, which is in accordance with the results of previous studies demonstrating that patients with better physical status require higher opioid dosages compared with those with poor physical status. ${ }^{12,19}$ Possible reasons for this tendency include increased sensitivity to local anesthetics, preexisting neuropathy in patients with metabolic diseases, such as diabetes mellitus, ${ }^{20}$ and decreased help-seeking behavior among patients with chronic illnesses. ${ }^{9}$ With regard to epidural opioids, lipophilic opioids, such as fentanyl, are considered appropriate analgesic agents, with rapid onset and fewer side effects than hydrophilic opioids; however, in comparison with the latter, epidural fentanyl covers only a relatively small area of the surgical dermatome. ${ }^{21}$ For this reason, thoracic or urogenital surgery, where the skin is incised parallel to the dermatome or the area of dermatome is relatively small, could be associated with a lower requirement of rescue analgesia compared with abdominal surgery.

Numbness and motor weakness are among the more common complications of PCEA, and higher concentrations of local anesthetics have been reported to increase the incidence of numbness and motor block..$^{22,23}$ The concentration of ropivacaine used in the present study $(0.1 \%-0.25 \%)$ is considered to be within the clinically acceptable range. ${ }^{24,25}$ Interestingly, the incidence of numbness and motor weakness among younger patients was substantially higher compared to the elderly. In addition, numbness or motor weakness was the most common cause for discontinuation of PCA among younger patients $(67.8 \%)$. These results suggest that younger patients might be more susceptible to changes in sensation and have lower tolerance for unpleasant feelings compared with elderly patients. In contrast, the proportion of elderly patients who discontinued PCA because of numbness or motor weakness was relatively low $(11.5 \%)$, which could possibly be because of the altered characteristics of sensory perception among the elderly, though the mechanism is not clear, ${ }^{26}$ or their tendency of not regarding a complication as problematic unless it is too serious. These factors might have caused a high proportion of cases of numbness/weakness to go unreported among the elderly patients. ${ }^{9,27}$ Further research might help explain these findings more clearly.

Elderly patients exhibited higher incidence of sedation and hypotension compared with younger patients in the present study. Though the anesthesiologists reduced the dosage of fentanyl administered to the elderly patients, a greater proportion of elderly patients $(1.4 \%$ vs $0.2 \%)$ were sedated in comparison with younger group. This might be explained by the increased sensitivity to and decreased metabolism of fentanyl among elderly patients. ${ }^{28,29}$ Several reports have described the hypotensive effects of EA. ${ }^{6,30,31}$ In addition, epidural administration of ropivacaine in combination with fentanyl has been reported to be associated with an increased incidence of hypotension. ${ }^{25,32}$ Decline in autonomic control and easier cephalic spread of epidural analgesics might explain the relatively high incidence of hypotension among the elderly patients, ${ }^{10,33}$ although the results may be debatable. ${ }^{34}$

According to previous studies, incidence of nausea and vomiting in patients receiving PCEA is not directly related to age.$^{35,36}$ In contrast, in the present study, the incidence of nausea and vomiting and requirement for rescue antiemetics among the elderly patients were higher compared to the younger patients. The higher incidence of hypotension among the elderly patients relative to the younger patients might have partly contributed to the higher incidence of nausea and vomiting among the former. In addition, nausea and vomiting were the most common causes of discontinuation of PCA among the elderly patients. With regard to the present results, improper management of nausea and vomiting in elderly patients might lead to failure of PCEA as a postoperative pain-management modality. The relationship between incidence of nausea and vomiting during PCEA and patient age requires further investigation.

This study had several limitations. Because of the retrospective study design, we could not precisely control the method or drug used for anesthesia or the specifics of epidural anesthesia, which might have influenced the present findings regarding adverse effects. However, given the large sample 
size, we believe that the present results are still reliable. In addition, such differences in preoperative characteristics, including types of anesthesia or surgery, may themselves be regarded as characteristics of elderly and young patients undergoing surgery. Another limitation is that most of the included patients were either South Korean or of Asian descent. Therefore, the present results might not be generalizable to other races or ethnicities.

According to the results of the present study, younger patients were more susceptible to numbness and motor weakness compared with the elderly, and these side effects were closely associated with discontinuation of PCA. Therefore, in young patients receiving fentanyl and ropivacaine-based PCEA, ensuring adequate dosage of fentanyl and avoiding excessive administration of ropivacaine appears to be a good strategy to increase the effectiveness of PCEA and decrease its associated adverse effects. On the other hand, in elderly patients receiving PCEA, reducing the dosage of the opioid rather than that of the local anesthetic and administration of preventive antiemetics are necessary in order to avoid sedation and nausea/vomiting. However, caution should be taken to avoid insufficient pain control.

\section{Conclusion}

In conclusion, there are differences in PCEA-related adverse effects and the associated risk factors between young and elderly patients. Therefore, in order to minimize the adverse effects of PCEA and enhance pain relief, different PCEA regimens and administration/prevention strategies should be considered for young and elderly patients.

\section{Author contributions}

All authors contributed toward data analysis, drafting and revising the paper and agree to be accountable for all aspects of the work.

\section{Disclosure}

The authors report no conflicts of interest in this work.

\section{References}

1. Liu S, Carpenter RL, Neal JM. Epidural anesthesia and analgesia: their role in postoperative outcome. Anesthesiology. 1995;82(6):1474-1506.

2. Catley DM, Thornton C, Jordan C, Lehane JR, Royston D, Jones JG. Pronounced, episodic oxygen desaturation in the postoperative period: its association with ventilatory pattern and analgesic regimen. Anesthesiology. 1985;63(1):20-28.

3. Crawford ME, Møiniche S, Orbaek J, Bjerrum H, Kehlet H. Orthostatic hypotension during postoperative continuous thoracic epidural bupivacaine-morphine in patients undergoing abdominal surgery. Anesth Analg. 1996;83(5):1028-1032.

4. Ergina PL, Gold SL, Meakins JL. Perioperative care of the elderly patient. World J Surg. 1993;17(2):192-198.
5. Swift CG. Pharmacodynamics: changes in homeostatic mechanisms, receptor and target organ sensitivity in the elderly. Br Med Bull. 1990; 46(1):36-52.

6. Mann C, Pouzeratte Y, Eledjam JJ. Postoperative patient-controlled analgesia in the elderly: risks and benefits of epidural versus intravenous administration. Drugs Aging. 2003;20(5):337-345.

7. Pöpping DM, Zahn PK, Van Aken HK, Dasch B, Boche R, PogatzkiZahn EM. Effectiveness and safety of postoperative pain management: a survey of 18925 consecutive patients between 1998 and 2006 (2nd revision): a database analysis of prospectively raised data. Br JAnaesth. 2008; 101(6):832-840.

8. Davis MP, Srivastava M. Demographics, assessment and management of pain in the elderly. Drugs Aging. 2003;20(1):23-57.

9. Clarke A, Martin D, Jones D, et al. "I try and smile, I try and be cheery, I try not to be pushy, I try to say 'I'm here for help' but I leave feeling ... worried": a qualitative study of perceptions of interactions with health professionals by community-based older adults with chronic pain. PLoS One. 2014;9(9):e105450.

10. Simon MJ, Veering BT, Stienstra R, van Kleef JW, Burm AG. The effects of age on neural blockade and hemodynamic changes after epidural anesthesia with ropivacaine. Anesth Analg. 2002;94(5):1325-1330.

11. Higuchi H, Adachi Y, Kazama T. Factors affecting the spread and duration of epidural anesthesia with ropivacaine. Anesthesiology. 2004; 101(2):451-460.

12. Tsui SL, Tong WN, Irwin M, et al. The efficacy, applicability and sideeffects of postoperative intravenous patient-controlled morphine analgesia: an audit of 1233 Chinese patients. Anaesth Intensive Care. 1996; 24(6):658-664.

13. Koh JC, Lee J, Kim SY, Choi S, Han DW. Postoperative pain and intravenous patient-controlled analgesia-related adverse effects in young and elderly patients: a retrospective analysis of 10,575 patients. Medicine (Baltimore). 2015;94(45):e2008.

14. Schenk MR, Putzier M, Kugler B, et al. Postoperative analgesia after major spine surgery: patient-controlled epidural analgesia versus patientcontrolled intravenous analgesia. Anesth Analg. 2006;103(5):1311-1317.

15. Wu CL, Cohen SR, Richman JM, et al. Efficacy of postoperative patient-controlled and continuous infusion epidural analgesia versus intravenous patient-controlled analgesia with opioids: a meta-analysis. Anesthesiology. 2005;103(5):1079-1088; quiz 1109-1010.

16. Goesling J, Brummett CM, Hassett AL. Cigarette smoking and pain: depressive symptoms mediate smoking-related pain symptoms. Pain. 2012;153(8):1749-1754.

17. Warner DO. Perioperative abstinence from cigarettes: physiologic and clinical consequences. Anesthesiology. 2006;104(2):356-367.

18. Hooten WM, Shi Y, Gazelka HM, Warner DO. The effects of depression and smoking on pain severity and opioid use in patients with chronic pain. Pain. 2011;152(1):223-229.

19. Gagliese L, Gauthier LR, Macpherson AK, Jovellanos M, Chan VW. Correlates of postoperative pain and intravenous patient-controlled analgesia use in younger and older surgical patients. Pain Med. 2008; 9(3):299-314.

20. Gebhard RE, Nielsen KC, Pietrobon R, Missair A, Williams BA. Diabetes mellitus, independent of body mass index, is associated with a "higher success" rate for supraclavicular brachial plexus blocks. Reg Anesth Pain Med. 2009;34(5):404-407.

21. Grass JA. Fentanyl: clinical use as postoperative analgesic-epidural/ intrathecal route. J Pain Symptom Manage. 1992;7(7):419-430.

22. Kim SH, Yoon KB, Yoon DM, Kim CM, Shin YS. Patient-controlled epidural analgesia with ropivacaine and fentanyl: experience with 2,276 surgical patients. Korean J Pain. 2013;26(1):39-45.

23. Halpern SH, Carvalho B. Patient-controlled epidural analgesia for labor. Anesth Analg. 2009;108(3):921-928.

24. Beilin Y, Galea M, Zahn J, Bodian CA. Epidural ropivacaine for the initiation of labor epidural analgesia: a dose finding study. Anesth Analg. 1999;88(6):1340-1345.

25. Lee BB, Ngan Kee WD, Lau WM, Wong AS. Epidural infusions for labor analgesia: a comparison of $0.2 \%$ ropivacaine, $0.1 \%$ ropivacaine, and 0.1\% ropivacaine with fentanyl. Reg Anesth Pain Med. 2002;27(1):31-36. 
26. Daoust R, Paquet J, Piette E, Sanogo K, Bailey B, Chauny JM. Impact of age on pain perception for typical painful diagnoses in the emergency department. J Emerg Med. 2016;50(1):14-20.

27. Stoller EP, Forster LE, Portugal S. Self-care responses to symptoms by older people: a health diary study of illness behavior. Med Care. 1993;31(1):24-42.

28. Scott JC, Stanski DR. Decreased fentanyl and alfentanil dose requirements with age: a simultaneous pharmacokinetic and pharmacodynamic evaluation. J Pharmacol Exp Ther. 1987;240(1):159-166.

29. Singleton MA, Rosen JI, Fisher DM. Pharmacokinetics of fentanyl in the elderly. Br J Anaesth. 1988;60(6):619-622.

30. Cashman JN, Dolin SJ. Respiratory and haemodynamic effects of acute postoperative pain management: evidence from published data. $\mathrm{Br} J$ Anaesth. 2004;93(2):212-223.

31. Nguyen MN,Zimmerman LH, Meloche K, et al. Hydromorphone vs fentanyl for epidural analgesia and anesthesia. Am J Surg. 2016;211(3):565-570.
32. Finucane BT, Ganapathy S, Carli F, et al. Prolonged epidural infusions of ropivacaine $(2 \mathrm{mg} / \mathrm{mL})$ after colonic surgery: the impact of adding fentanyl. Anesth Analg. 2001;92(5):1276-1285.

33. Cleophas TJ, van Marum R. Age-related decline in autonomic control of blood pressure: implications for the pharmacological management of hypertension in the elderly. Drugs Aging. 2003;20(5):313-319.

34. Liu SS, Allen HW, Olsson GL. Patient-controlled epidural analgesia with bupivacaine and fentanyl on hospital wards: prospective experience with 1,030 surgical patients. Anesthesiology. 1998;88(3):688-695.

35. Wu HY, Gong CS, Lin SP, Chang KY, Tsou MY, Ting CK. Predicting postoperative vomiting among orthopedic patients receiving patientcontrolled epidural analgesia using SVM and LR. Sci Rep. 2016; 6:27041.

36. Chen YJ, Chang KY, Tsou MY, Lin SP, Chan KH, Ting CK. Risk factors of vomiting among females on patient-controlled epidural analgesia. J Chin Med Assoc. 2009;72(4):183-187.

\section{Publish your work in this journal}

The Journal of Pain Research is an international, peer reviewed, open access, online journal that welcomes laboratory and clinical findings in the fields of pain research and the prevention and management of pain. Original research, reviews, symposium reports, hypothesis formation and commentaries are all considered for publication.

\section{Dovepress}

The manuscript management system is completely online and includes a very quick and fair peer-review system, which is all easy to use. Visit http://www.dovepress.com/testimonials.php to read real quotes from published authors. 